\title{
Root distribution and its association with bean growth habit
}

\author{
LUIS P.S. VELHO, RITA C. DE MELO, JOÃO PEDRO F. BERNARDY, SIBILA \\ GRIGOLO, ALTAMIR F. GUIDOLIN and JEFFERSON L.M. COIMBRA
}

Departamento de Agronomia, Universidade do Estado de Santa Catarina/UDESC, Instituto de Melhoramento e Genética Molecular/IMEGEM, Avenida Camões, 2090, 88520-000 Lages, SC, Brazil

Manuscript received on May 8, 2017; accepted for publication on December 20, 2017

\begin{abstract}
Associations between root distribution and bean growth habit may contribute to the selection of genotypes adapted to restrictive environments. The present work aimed to relate and compare root distribution with the growth habit in beans. 10 bean genotypes of different growth habits (I, II and III) were evaluated for root distribution in two agricultural years (2014/15 and 2015/16). The genotypes responded similarly for the trait root distribution throughout the agricultural years, without any simple effect of the genotype $\mathrm{x}$ year interaction. The factors genotype and years were significant for the trait. The genotypes of a determinate habit showed significant differences compared to other genotypes (II and III), which were ascribed to their poor performance in the average of years. They include the Carioca Precoce, which showed a behavior similar to the other habits. It could be considered a "plastic" genotype under restrictive conditions. The contrasts revealed significant differences between the growth habits II $v s$ I (2.87) and III $v s$ I (3.64) for root distribution. The differences were also significant for grain yield. Thus, genotypes of indeterminate growth habit show greater root distribution than those of a determinate habit, regardless of the agricultural years. Therefore, they are promising for use in blocks of crosses, when the purpose is the selection of cultivars adapted to low input environments.
\end{abstract}

Key words: Abiotic stresses, contrasts, genotype x environment interaction, Phaseolus vulgaris L.

\section{INTRODUCTION}

Beans (Phaseolus vulgaris L.) show great sensitivity to abiotic factors, thus, hindering the expression of their productive potential (Assefa et al. 2015, Urrea et al. 2009). Such factors include water deficiency and nutrient-poor soils, which are the main causes for reduced agricultural production (Guimarães et al. 2011). The occurrence of high climatic instabilities, low investment in the crop

Correspondence to: Rita Carolina de Melo

E-mail: rita_carol_mel@hotmail.com and forecasts about the finite fertilizer reserves are factors that prove the relevance of the search for genotypes adapted to such conditions (Wasson et al. 2012).

Changes in root architecture (depth, efficiency and distribution, for example) have been effective in capturing and allocating resources for plant growth and development, which indirectly leads to tolerance to abiotic stresses (Lynch 1995, 2007, 2014, da Silva and Delatorre 2009, Miguel et al. 2013, de Melo et al. 2016). However, breeding programs have exhaustively targeted the selection 
of genotypes only considering the traits of the aerial part of the plant, while little attention has been paid to the study on root distribution, especially under field conditions (Miguel et al. 2013, Toaldo et al. 2013, de Melo et al. 2016).

Knowledge about root distribution and its relation with other traits can provide satisfactory gains in the selection of ideotypes. There is no one bean plant ideotype that does well in all environments and for this reason, plant growth habit, which is closely tied to plant adaptation and yield, is a critical aspect of selection in the development of cultivars. For example, bean plants presenting type I growth habit (determinate), have smaller size. It suggests that the energy demand for the development of the aerial part is also lower, when compared to plants with indeterminate growth habit (II and III) (Kelly 1998). This may increase assimilate supply for the development of the root system. However, these plants have a smaller cycle compared to the other habits, and the development of the root system may cease within few weeks (Singh 1981, Kelly 1998). Thus, genotypes with this determinate growth habit are probably more sensitive to climate change.

A few studies are found in the literature that relate and compare growth habit and root distribution in bean culture. Cichy et al. 2009 characterize the impact of growth habit on root architecture and plant performance including $\mathrm{P}$ uptake, seed yield, and P use efficiency. Thus, knowledge about the relationship between growth habit and root distribution would facilitate the selection of linages that are high productivity and tolerant to abiotic stresses. Therefore, the present work aimed to relate and compare root distribution with different growth habits in beans.

\section{MATERIALS AND METHODS}

\section{DESCRIPTION OF THE TRIAL}

The experiment was carried out in the agricultural years of 2014/15 and 2015/16 in Lages - SC, Brazil. According to Koppen classification, climate was temperate $\mathrm{cfb}$ (moist mesothermal and mild summer). The tests were carried out in a soil classified as Inceptisol Udepts Humudepts, with a moderate A horizon, clayey texture and undulating relief.

In the agricultural year 2014/15, the following eight bean genotypes with distinct growth habits were assessed:

i) Type I: CHIB 06, BRS Radiante and Carioca Precoce;

ii) Type II: BAF 07, IPR 139, IPR Tangará, FTS Soberano;

iii) Type III: BAF 45.

According to the classification of the International Center of Tropical Agriculture (CIAT 1985), the growth habits classified as: i) Type I: shrub determinate growth habit, the plants cease the vegetative growth after the insertion of the first floral bud; ii) Type II: shrub indeterminate growth habit, plants continue their vegetative growth after flowering. They emit few branches and their branches do not emit guides and iii) Type III: prostrate indeterminate growth habit, with well developed branch ending in guides. In general, plants with indeterminate growth habit have higher total cycle and height of plants in relation to the determinate growth habit.

In the agricultural year 2015/16, two other Type II linages (Population 1 and Population 10) were included in addition to the eight genotypes previously described. These two populations were in the $\mathrm{F}_{7}$ generation (high homozygous level). These linages were obtained from artificial hybridizations targeting at the selection of populations with greater root distribution. 
The experiment was arranged in a randomized block design, with three replications. The experimental unit was composed of six lines of four meters with spacing between lines of $0.50 \mathrm{~m}$ and between plots of $0.90 \mathrm{~m}$, as follows:

i) In the four central rows of the plot, a density of 10 seeds per linear meter was used, and grain yield was measured.

ii) In the two external lines, a spacing of 0.50 $\mathrm{m}$ between plants was used to assess the root system.

The experiment was conducted using conventional procedures, the soil was revolved and the cultural treatments were performed according to the needs of the soil and crop. Manual weeding was also carried out.

\section{ASSESSMENT OF ROOT SYSTEM AND GRAIN YIELD}

When the genetic constitutions showed full flowering (occurrence of maximum root growth), profiles perpendicular to the sowing line were opened at $0.05 \mathrm{~m}$ of the plants, and the roots were exposed with a sharp tool, as described by Bohm (1979). Then, a $0.50 \mathrm{~m}$ wide and $0.30 \mathrm{~m}$ high rectangle was placed on the profile, subdivided into squares with $0.05 \mathrm{~m}$ on each side. Root distribution was determined in the binary system (denomination of presence (1) and absence (0) of the roots in each square). To capture the image of the root distribution, a digital camera was used, positioned $0.6 \mathrm{~m}$ from the grid. The image was used to assess root distribution in the layers $0-0.10 \mathrm{~m}, 0.10 \mathrm{~m}$ $0.20 \mathrm{~m}$ and $0.20-0.30 \mathrm{~m}$.

Grain yield $\left(\mathrm{kg} \mathrm{ha}^{-1}\right)$ was determined in the useful area of the plot (four central lines), disregarding $0.50 \mathrm{~m}$ used as border.

\section{STATISTICAL ANALYSIS}

The data were analyzed in the PROC GLIMMIX (Generalized Linear Mixed Model) procedure of the SAS (Statistical Analysis System, version 9.2), according to the respective mathematical model type I:

$$
\mathrm{Y}_{\mathrm{ijkl}}=\mu+\mathrm{blc}_{\mathrm{i}}+\text { gen }_{\mathrm{j}}+\mathrm{ano}_{\mathrm{k}}+\text { gen }^{*} \mathrm{ano}_{\mathrm{jk}}+\mathrm{e}_{\mathrm{ijkl}}
$$

$\mathrm{Y}_{\mathrm{ijkl}}$ - observed values for the response variable in the 1 -th experimental unit in the $\mathrm{i}$-th block in the $\mathrm{j}$-th genotype for the k-th year; $\mu$ - is the effect of the general mean; blc $c_{i}$ is the fixed effect of the $i$-th level of the block factor; gen $n_{j}$ is the fixed effect of the $j$-th level of the genotype factor; $\mathrm{ano}_{\mathrm{k}}$ is the fixed effect of the k-th level of the year factor, gen*ano ${ }_{j k}$ is the fixed effect of the interaction of the $j$-th level of the genotype factor with the k-th level of the year factor and $\mathrm{e}_{\mathrm{ijkl}}$ - effect of the residue.

\section{Root distribution}

In many practical situations, the variable of response does not assume a normal distribution. The evaluation of root distribution in binomial scale (presence $=1$ and absence $=0$ of root in each square) performed in the present study, is an example. The Generalized Linear Mixed Model was used to meet the model assumptions. Therefore, its main objective is to define the scale on which a linear additive model occurs; in the present case, the definition of the binomial scale (Littell et al. 2006). The Logit Link Function was used to display the data on the inverse scale. In addition, root distribution has correlated error structures, since the evaluations are performed throughout the space (depths) in the same genotype. Thus, the structure of residual variances and covariances was adjusted, based on linearizations. The default estimation method in GLIMMIX known as restricted pseudo-likelihood (RPL) was utilized. The best structure was selected according to the Akaike-AIC information criterion.

Average multiple comparisons were performed to discriminate the genotypes for root distribution. In order to discriminate the associations between growth habit and root distribution, non-orthogonal 
contrasts between genetic constitutions were performed, according to the following comparison scheme: i) Type II vs Type I, ii) Type III vs Type II and iii) Type II $v s$ Type III for agricultural years.

\section{Grain Yield}

The homogeneity of variances for the trait grain yield was verified with the COVTEST argument, in the GLIMMIX procedure. Due to the variance heterogeneity observed, the structure of residual variances and covariances was adjusted to meet the assumptions of the model, based on linearizations. The default estimation method in GLIMMIX known as restricted pseudo-likelihood (RPL) was utilized. The best structure was selected in compliance with the Akaike-AIC information criterion, and the $\mathrm{UCH}$ matrix obtained the lowest value. In order to verify the associations between growth habit and grain yield, non-orthogonal contrasts between the genetic constitutions were performed, according to the following comparison scheme: $i$ ) Type II $v s$ Type I; ii) Type III vs Type II; and iii) Type II vs Type III for the agricultural years.

\section{RESULTS AND DISCUSSION}

The structures of residual variance and covariance matrices were assessed according to the Akaike criterion. The first-order autoregressive matrix AR (1) presented the lowest value. Thus, it was selected for the adjustment of the mathematical model for root distribution. According to the analysis of variance, genotype x year interaction was not significant (Table I), which highlighted the similar behavior of these genotypes in the two agricultural years. Probably, the evaluated genotypes responded similarly to the change in the environments, which reveals the same pattern of root distribution in both agricultural years, 2014/15 and 2015/16, and no changes in the classification of these genotypes. In other words, the effects of genotypes and agricultural years are additive and there is no interaction between them (Mather and Jinks 1977). This fact is desirable in genetic breeding for facilitating plant selection and recommendation of genotypes with broad adaptability.

The block factor revealed significant effect $(\mathrm{P}=0.0299)$. It implies that the blocking fator had a large effect and that the noise reduction obtained by blocking was probably helpful in improving the precision of the comparison between treatments. The analysis of variance revealed differential effect of genotypes for root distribution. Possibly, the different genotypes (and their growth habits) present genetic variability for the trait under study, which indicates that selection can provide satisfactory genetic gains (Lynch and Brown 2012). Since no interaction between the main factors was observed, the selection can be performed in any year (Table I).

The main factor agricultural year also showed significant difference, and the mean root distribution of the agricultural years (2014/15 and 2015/16) differed significantly (Table I), regardless of the genotype effects. In general, the average root distribution in the agricultural year of 2015/16 was lower, compared to the year $2014 / 15$, due to the effect of climate conditions. According to Conab reports (2016), the first bean crop cultivated in the State of Santa Catarina was hampered by the excessive amount of rain during the development cycle of the crop. Excessive rain not only hinders the development of the aerial part of the plants, but

TABLE I

Analysis of variance for the fixed effects for the trait root distribution. Probability values (F) corresponding to 10 bean genotypes evaluated in the agricultural years 2014/15 and 2015/16.

\begin{tabular}{cccr}
\hline $\begin{array}{c}\text { Causes of } \\
\text { variation }\end{array}$ & $\begin{array}{c}\text { Degrees of } \\
\text { freedom }\end{array}$ & F Value & \multicolumn{1}{c}{$\operatorname{Pr}>\mathrm{F}$} \\
\hline Block & 2 & 3.51 & 0.0299 \\
Genotype & 9 & 4.15 & $<0.0001$ \\
Year & 1 & 34.58 & $<0.0001$ \\
Genotype*Year & 7 & 0.58 & 0.7720 \\
\hline
\end{tabular}


TABLE II

Significant minimum difference in averages between eight genotypes of beans of different growth habits (I, II and III) for the trait root distribution. The estimates are expressed in logistic scale $\mu \mathrm{T}$ (above the diagonal) and original scale $\mu \mathrm{O}$ (below the diagonal) in the average of the agricultural years 2014/15 and 2015/16.

\begin{tabular}{|c|c|c|c|c|c|c|c|c|}
\hline Genotype $^{\mathrm{a}}$ & $1-\mathrm{II}(0.45)$ & $2-$ III $(0.44)$ & $3-\mathrm{II}(0.38)$ & 4 - II (0.39) & 5 - II $(0.41)$ & $6-I(0.30)$ & $7-\mathrm{I}(0.26)$ & $8-\mathrm{I}(0.34)$ \\
\hline $1-$ II $(0.45)$ & - & 0.06 & 0.32 & 0.27 & 0.20 & $0.66^{*}$ & $0.88 *$ & $0.48 *$ \\
\hline 2 - III (0.44) & 0.01 & - & 0.26 & 0.21 & 0.13 & $0.60 *$ & $0.82 *$ & $0.42 *$ \\
\hline $3-$ II (0.38) & 0.08 & 0.06 & - & -0.04 & -0.12 & 0.34 & $0.56^{*}$ & 0.15 \\
\hline 4 - II (0.39) & 0.07 & 0.05 & -0.02 & - & -0.07 & $0.38 *$ & $0.61 *$ & 0.20 \\
\hline $5-$ II $(0.41)$ & 0.05 & 0.03 & -0.03 & -0.02 & - & $0.46^{*}$ & $0.68 *$ & 0.28 \\
\hline $6-\mathrm{I}(0.30)$ & 0.15 & 0.14 & 0.07 & 0.09 & 0.10 & - & 0.22 & -0.18 \\
\hline $7-\mathrm{I}(0.26)$ & 0.20 & 0.18 & 0.12 & 0.13 & 0.11 & 0.04 & - & $-0.40 *$ \\
\hline $8-I(0.34)$ & 0.11 & 0.10 & 0.04 & 0.05 & 0.06 & -0.04 & -0.08 & - \\
\hline
\end{tabular}

${ }^{\mathrm{a}}$ Genotypes assessed and their respective growth habits (I, II or III) and original averages $\mu \mathrm{O}(0$ - 1): 1 - BAF 07, 2 - BAF 45, 3 IPR 139, 4 - IPR Tangará, 5 - FTS Soberano, 6 - CHIB 06, 7 - BRS Radiante and 8 - Carioca Precoce.

* Significant at 0.05 error probability by the Tukey test.

also directly reduces the root system. Although root distribution is an inheritable trait, it is complex and highly affected by the effects of the environment (Miguel et al. 2015).

Since the effect of the interaction between the factors did not reveal any significant difference, the interest resides in the study on genotype effects (and their different growth habits) on the mean of the agricultural years. Table II presents the minimum significant difference between the (transformed and original) means of eight bean genotypes that were assessed in the two agricultural years. The genotype BRS Radiante, whose growth habit is type I, revealed significant differences from the other genotypes of habits types II and III, in $86 \%$ of the comparisons. Similarly, CHIB 06 presented nearly $70 \%$ of the significant comparisons. On the other hand, Carioca Precoce showed difference in only $43 \%$ of the comparisons with the other genotypes of types II and III.

Carioca Precoce showed the highest average root distribution among the genotypes with determinate habit, $\mu \mathrm{O}=0.34$ (original scale). In other words, around $30 \%$ of the squares contained roots, compared to the others. In addition, this genotype presented significant difference only for

\section{TABLE III}

Contrasts between (types I, II and III) bean growth habits for the traits root distribution (above the diagonal) and grain yield (below the diagonal) in the average of the agricultural years 2014/15 and 2015/16.

\begin{tabular}{cccc}
\hline Growth habits & Type I & Type II & Type III \\
\hline Type I & - & $2.87^{*}$ & $3.64^{*}$ \\
Type II & $3660^{*}$ & - & -0.77 \\
Type III & $3528^{*}$ & 132 & - \\
\hline
\end{tabular}

* Significant at 0.05 error probability by the $\mathrm{t}$ test $\mathrm{H}_{0}: \mu_{1}-\mu_{2}=$ 0 . $\mathrm{H}_{\mathrm{A}}: \mu_{1}-\mu_{2} \neq 0$.

two genotypes of indeterminate habit (BAF 07 and BAF 45). Therefore, it can be considered more "plastic", for presenting root distribution similar to a genotype of habit type II, which is known to be cultivated in most agricultural regions (Table II). Besides, the genotype Carioca Precoce revealed significant differences from only BRS Radiante (genotype with the worst average performance), when evaluated in 2015/16. Possibly, under restrictive environmental conditions (which was observed in the agricultural year of 2015/16), the metabolic cost for the growth and development of the root distribution of genotypes of type I habit (such as Carioca Precoce) is similar to that of genotypes of habit of types II and III. 
In general, genotypes of growth habit type I presented significant differences from the others (Table II). This fact is mainly due to their lower root distribution $(\mu \mathrm{O}=0.26$ to 0.34 ). Plants with low root distribution show low nutrient uptake capacity, especially phosphorus, due to its poor mobility in the soil solution. Besides, they are more susceptible to damage caused by water stress (Beebe et al. 2008, Miguel et al. 2013).

The only genotype of growth habit type III (BAF 45) showed significant differences from all genotypes of habit type I. In addition, it did not reveal significant differences from any genotype of type II habit, considering the two agricultural years. Thus, BAF 45 can be considered a desirable alternative for producers that search for genotypes with longer cycle and less sensitivity to restrictive environmental conditions (Table II).

No significant differences were observed between the genotypes of type II growth habit. Regardless of the genotype involved, the mean root distribution was similar. This reveals the genetic potential of genotypes such as BAF 07 (Germplasm Bank access) to the trait root distribution, which presented the same performance when compared to the genotypes IPR 139, IPR Tangará and FTS Soberano (cultivars present in the market). Studies on root system breeding performed previously point to BAF 07 as a promising parent in blocks of crosses, due to the high expressiveness of genes responsible for root distribution in their offspring.

Genotype IPR Tangará (type II) revealed significant differences only with CHIB 06 and BRS Radiante (genotypes with the worst mean performance $\mu \mathrm{O}=0.30$ and $\mu \mathrm{O}=0.26$, respectively) in the average of the agricultural years. However, if we consider its individual performance, year by year, it can be verified that it also differed from the genotype BAF 07 (type II) in 2014/15. This highlights the non-significant genotype $\mathrm{x}$ year interaction, since the differences observed in each year are due to the relative performance of other genotypes, whose root distribution is superior, especially under favorable agricultural years (2014/15).

It is also noted that the genotypes IPR 139, IPR Tangará and FTS Soberano did not reveal any significant differences. These genotypes are promising for use in crossbreeding blocks or even for cultivation by farmers in environments under water stress and low nutrient availability. According to Lynch (2014), plants with a root system well distributed in the soil show more efficiency in nutrient absorption and water acquisition, which avoids high metabolic cost.

The comparison and relationship between the different growth habits for the trait root distribution can be better explained by comparing the averages. In addition, it allows identifying relationships between the adaptation of the plants to the different environments and cropping systems, including the productive traits (grain yield) (Singh 2001). Thus, for the purposes of comparison, the genotypes can be grouped according to their growth habit (types I, II and III) in order to identify the association with the trait root distribution.

The genotypes with determinate growth habit were significantly different from those of type II indeterminate growth habit (Table III). The contrast II $v_{s}$ I was positive. It must be highlighted that the root distribution of type II habit is superior to that of type I habit. This fact is also verified for the trait grain yield, and the difference can reach 3660 $\mathrm{kg} \mathrm{ha}^{-1}$. This highlights that high grain yield and good adaptation to low input environments (water stress and low availability of nutrients) can be brought together in a single genetic constitution. According to Beebe et al. (2013), genotypes with types II and III growth habit are more resistant to drought than types I and IV, since they have better root distribution, which increases their efficiency in the acquisition of water from soil for transpiration. In addition, plants with an indeterminate growth habit have higher productive potential than plants 
of determinate habit because they produce more vegetables per plant and more seeds per pod (Dawo et al. 2007, Zilio et al. 2011).

Similarly, the contrast between means III vs I was significant. Genotypes of type I were inferior to those of type III, both for root distribution and grain yield (Table III). Possibly, selecting genotypes with type I growth habit reduces the chances of obtaining superior genetic constitutions for these traits. In general, plants of indeterminate habit are taller, which requires a larger root system for sustentation. Genotypes of type III indeterminate habit present greater mass, area and root length, compared to the genotypes of groups I and IV in soils with unlimited supply of phosphorus (Trindade and Araújo 2014). However, they may express a less stable grain yield due to greater susceptibility to diseases (Soltani et al. 2016).

However, the contrast of the averages of II vs III showed no significant difference for both traits. This fact highlights the similarity between these types of beans. According to Mekbib (2003), genotypes of groups II and III are more resilient under stress conditions. Thus, grain yield is less affected.

The average performance of the genetic constitutions in 2015/16 was severely affected, since differences between the growth habits for grain yield could not be verified in any comparison. In addition, the genetic constitutions revealed low averages for this trait. This year was characterized by restrictive environmental conditions for the crop. This fact suggests that, in hostile environments, the performance of highly productive genotypes is significantly reduced and come close to the performance of lower genetic constitutions. Root distribution, in turn, even in lower environments, can be easily discriminated among the genotypes, according to their growth habit. This corroborates that root distribution is related to growth habit and plays an important role in bean adaptation under abiotic stress conditions.

\section{CONCLUSIONS}

The root distribution is related to growth habit in beans. Bean genotypes with indeterminate growth habit have greater root distribution, compared to those of determinate habit.

\section{ACKNOWLEDGMENTS}

To the Universidade do Estado de Santa Catarina (UDESC), Conselho Nacional de Desenvolvimento Científico e Tecnológico (CNPq), Coordenação de Aperfeiçoamento de Pessoal de Nível Superior (CAPES) and Fundação de Apoio à Pesquisa Científica e Tecnológica do Estado de Santa Catarina (FAPESC) for the scholarship granting and financial support fot the development of the presente work.

\section{REFERENCES}

ASSEFA T, WU J, BEEBE SE, RAO IM, MARCOMIN D AND CLAUDE RJ. 2015. Improving adaptation to drought stress in small red common bean: phenotypic differences and predicted genotypic effects on grain yield, yield components and harvest index. Euphytica 203(3): 477-489.

BEEBE SE, RAO IM, BLAIR MW AND ACOSTAGALLEGOS JA. 2013. Phenotyping common beans for adaptation to drought. Front Physiol 4(35): 1-20.

BEEBE SE, RAO IM, CAJIAO C AND GRAJALES M. 2008. Selection for drought resistance in common bean also improves yield in phosphorus-limited and favorable environments. Crop Sci 48(2): 582-592.

BOHM W. 1979. Methods of studying root systems. Berlin: Springer, $188 \mathrm{p}$.

CIAT - CENTRO INTERNACIONAL DE AGRICULTURA TROPICAL. 1985. Frijol: Investigación y Producción. Available at: http://pdf.usaid.gov/pdf_docs/PNABF466. pdf. Accessed on September 20, 2017.

CICHY KA, SNAPP SS AND BLAIR MW. 2009. Plant growth habit, root architecture traits and tolerance to low soil phosphorus in an Andean bean population. Euphytica 165(2): 257-268.

CONAB - COMPANHIA NACIONAL DE ABASTECIMENTO. 2016. Follow-up of the Brazilian grain harvest. Acompanhamento da safra brasileira de grãos. Available at: http://www.conab.gov.br. Accessed on November 23, 2016. 
DA SILVA AA AND DELATORRE CA. 2009. Root architecture modification in response to phosphorus and nitrogen availability. Rev Ciênc Agrovet 8(2): 152-163.

DAWO MI, SANDERS FE AND PILBEAM DJ. 2007. Yield, yield components and plant architecture in the $\mathrm{F}_{3}$ generation of common bean (Phaseolus vulgaris L.) derived from a cross between the determinate cultivar 'Prelude' and an indeterminate landrace. Euphytica 156(1-2): 77-87.

DE MELO RC, SCHMIT R, CERUTTI P, GUIDOLIN AF AND COIMBRA JLM. 2016. Genetic variation in the trait root distribution over segregating generations of common bean. Euphytica 207(3): 665-674.

GUIMARÃES CM, STONE LF, PELOSO MJD AND OLIVEIRA JP. 2011. Common bean genotypes under water stress. Rev Bras Eng Agríc Ambient 15(7): 649-656.

KELLY JD. 1998. Bean root - A plant breeder's perspective. Annual report of the bean improvement. Available at: https://naldc.nal.usda.gov/naldc/download.xhtml?id=IND 21814159\&content=PDF. Accessed on December 1, 2016.

LITTELL RC, MILLIKEN GA, STROUP WW, WOLFINGER RD AND SHABENBERGER O. 2006. SAS $^{\circledR}$ for mixed models. Cary: SAS Institute, 814 p.

LYNCH JP. 1995. Root architecture and plant productivity. Plant Physiol 109: 7-13.

LYNCH JP. 2007. Roots of the second green revolution. Aust J of Bot 55(5): 493-512.

LYNCH JP. 2014. Root phenes that reduce the metabolic costs of soil exploration: opportunities for $21^{\text {st }}$ century agriculture. Plant Cell Environ 38(9): 1775-1784.

LYNCH JP AND BROWN KM. 2012. New roots for agriculture: exploiting the root phenome. Philos T Roy Soc B 367(1595): 1598-1604.

MATHER K AND JINKS JL. 1977. Introduction to Biometrical Genetics. London: Chapman and Hall Ltd., 231 p.

MEKBIB F. 2003. Yield stability in common bean (Phaseolus vulgaris L.) genotypes. Euphytica 130(2): 147-153.

MIGUEL MA, POSTMA JA AND LYNCH JP. 2015. Phene synergism between root hair length and basal root growth angle for phosphorus acquisition. Plant Physiol 167(4): 1430-1439.
MIGUEL MA, WIDRIG A, VIEIRA RF, BROWN KM AND LYNCH JP. 2013. Basal root whorl number: a modulator of phosphorus acquisition in common bean (Phaseolus vulgaris L.). Ann of Bot 112(6): 973-982.

SINGH SP. 1981. A key for identification of different growth habits of Phaseolus vulgaris L. Centro Internacional de Agricultura Tropical (CIAT). Available at: https:// cgspace.cgiar.org/bitstream/handle/10568/72290/66927. pdf? sequence $=1 \&$ is Allowed $=y$. Accessed on December 1,2016 .

SINGH SP. 2001. Broadening the genetic base of common bean cultivars: A review. Crop Sci 41(6): 1659-1675.

SOLTANI A, BELLO M, MNDOLWA E, SCHRODER S, MOGHADDAM SM, OSORNO JM, MIKLAS PN AND MCCLEAN PE. 2016. Targeted analysis of dry bean growth habit: Interrelationship among architectural, phenological, and yield components. Crop Sci 56(6): 3005-3015.

TOALDO D, MORAIS PPP, BATTILANA J, COIMBRA JLM AND GUIDOLIN AF. 2013. Selection in early generations and the occurrence of heterosis for the character root distribution. Euphytica 190(3): 335-344.

TRINDADE RS AND ARAÚJO AP. 2014. Variability of root traits in common bean genotypes at different levels of phosphorus supply and ontogenetic stages. Rev Bras Ciênc Solo 38(4): 1170-1180.

URREA CA, YONTS CD, LYON DJ AND KOEHLER AE. 2009. Selection for drought tolerance in dry bean derived from the Mesoamerican gene pool in western Nebraska. Crop Sci 49(6): 2005-2010.

WASSON AP, RICHARDS RA, CHATRATH R, MISRA SC, SAI PRASAD SV, REBETZKE GJ, KIRKEGAARD JA, CHRISTOPHER J AND WATT M. 2012. Traits and selection strategies to improve root systems and water uptake in water-limited wheat crops. J Exp Bot 63(9): 3485-3498.

ZILIO M, COELHO CMM, SOUZA CA, SANTOS JCP AND MIQUELLUTI DJ. 2011. Contribution of the yield components to grain yield of common beans (Phaseolus vulgaris L.) landrace genotypes. Rev Ciênc Agron 42(2): 429-438. 